\title{
Surgical Management of Hearts with Isomeric Atrial Appendages
}

\author{
Ujjwal Chowdhury $^{1}$, Robert Anderson ${ }^{2}$, Diane E. Spicer ${ }^{3}$, Lakshmi Sankhyan ${ }^{4}$, Niraj \\ Pandey $^{1}$, Shikha Goja ${ }^{1}$, Palleti Rajashekar ${ }^{1}$, Balaji Arvind ${ }^{1}$, and Doniparthi Pradeep ${ }^{1}$ \\ ${ }^{1}$ All India Institute of Medical Sciences Cardio-Thoracic Sciences Centre \\ ${ }^{2}$ Newcastle University \\ ${ }^{3}$ Johns Hopkins All Children's Hospital Heart Institute \\ ${ }^{4}$ Department of Cardiothoracic Surgery All India Institute of Medical Sciences Bilaspur \\ Himachal Pradesh
}

January 3, 2022

\begin{abstract}
Background and aim: On the basis of previously published accounts, coupled with our own experience, we have assessed the surgical approaches to patients with isomeric atrial appendages. Methods: We reviewed pertinent published studies on surgical treatment of individuals with isomeric atrial appendages, with the pertinent surgical details provided by most of the manuscripts. Results: Half of patients with right isomerism, and two-thirds of those with left isomerism have bilateral superior caval veins. Azygos extension of the inferior caval vein is reported in three-quarters of those with left isomerism. The coronary sinus is universally absent in right isomerism, along with totally anomalous pulmonary venous connection, and is absent in two-fifths of those with left isomerism.. Univentricular atrioventricular connections are expected in up to three-quarters of those with right isomerism. Atrioventricular septal defect is reported in up to four-fifths, more frequently in right isomerism, with such patients typically having discordant ventriculoatrial connections or double outlet right ventricle. Reported mortalities extend to $85 \%$ for those with right, and $50 \%$ for those with left isomerism. In right isomerism, mortality is up to $54 \%$ for systemic-to-pulmonary arterial shunting, up to $75 \%$ for univentricular repair, and up to $95 \%$ for repair of totally anomalous pulmonary venous connection itself. No more than one-quarter had undergone Fontan completion, with reported mortalities of $21 \%$. Conclusion: Early surgical results are satisfactory in patients with left isomerism, but disappointing for those with right. Recent advances in cardiac and liver transplantation may offer improved survival.
\end{abstract}

\section{Surgical Management of Hearts with}

Isomeric Atrial Appendages

Running title: Isomeric Atrial Appendages

Ujjwal Kumar Chowdhury, MCh, Diplomate NB ${ }^{1}$

Robert H. Anderson, BSc, MD, PhD (Hon), FRCPath, FRCS Ed (Hon) ${ }^{2}$

Diane E. Spicer, BSc ${ }^{3}$

Lakshmi Kumari Sankhyan, $\mathrm{MCh}^{4}$

Niraj Nirmal Pandey, DM ${ }^{1}$

Shikha Goja, MS ${ }^{1}$

Palleti Rajasekar, $\mathrm{MCh}^{\mathbf{1}}$

Balaji Arvind, DM ${ }^{1}$ 


\section{Doniparthi Pradeep, $\mathrm{MCh}^{1}$}

Cardiothoracic Centre, All India Institute of Medical Sciences, New Delhi ${ }^{1}$ and Bilaspur, Himachal Pradesh ${ }^{4}$

Institute of Biomedical Sciences ${ }^{2}$, Newcastle University, Newcastle-upon-Tyne, United Kingdom

${ }^{3}$ Heart Institute, Johns Hopkins All Children's Hospital, St. Petersburg, Florida, USA and Department of Pediatric Cardiology, University of Florida, Gainesville, Florida, USA

Correspondence:

\section{Dr. Ujjwal Kumar Chowdhury, M.Ch., Diplomate NB}

Professor

Department of Cardiothoracic and Vascular Surgery

AIIMS, New Delhi-110029, INDIA

Tel.: 91-11-26594835

Fax: 91-11-26588641

Email: ujjwalchowdhury@gmail.com

Orcid ID: http: //orcid.org/0000-0002-1672-1502

Word Count: Abstract (243), Text (4256), References (1777), Figure Legends (890)

Statement of human rights/ethical approval: The authors assert that all procedures contributing to this study comply with the ethical standards of the relevant national guidelines on human experimentation and with the Helsinki declaration of 1975, as revised in 2008.

Conflict of interest : Nil

Source of funding : Nil

Availability of Data: Data available in the cited materials

\section{Abstract}

Background and aim: On the basis of previously published accounts, coupled with our own experience, we have assessed the surgical approaches to patients with isomeric atrial appendages.

Methods : We reviewed pertinent published studies on surgical treatment of individuals with isomeric atrial appendages, with the pertinent surgical details provided by most of the manuscripts.

Results : Half of patients with right isomerism, and two-thirds of those with left isomerism have bilateral superior caval veins. Azygos extension of the inferior caval vein is reported in three-quarters of those with left isomerism. The coronary sinus is universally absent in right isomerism, along with totally anomalous pulmonary venous connection, and is absent in two-fifths of those with left isomerism.. Univentricular atrioventricular connections are expected in up to three-quarters of those with right isomerism. Atrioventricular septal defect is reported in up to four-fifths, more frequently in right isomerism, with such patients typically having discordant ventriculoatrial connections or double outlet right ventricle. Reported mortalities extend to $85 \%$ for those with right, and $50 \%$ for those with left isomerism. In right isomerism, mortality is up to $54 \%$ for systemic-to-pulmonary arterial shunting, up to $75 \%$ for univentricular repair, and up to $95 \%$ for repair of totally anomalous pulmonary venous connection itself. No more than one-quarter had undergone Fontan completion, with reported mortalities of $21 \%$.

Conclusion : Early surgical results are satisfactory in patients with left isomerism, but disappointing for those with right. Recent advances in cardiac and liver transplantation may offer improved survival. 
Key words: Asplenia, Functionally univentricular heart, Hepatopulmonary and portopulmonary syndrome, Isomerism of atrial appendages, Left isomerism, Obstructed anomalous pulmonary venous connection, Polysplenia, Right isomerism, Visceral heterotaxy

\section{Introduction}

Described initially as "Ivemark syndrome", there is still no agreement as how best to segregate individuals with jumbled-up thoracic and abdominal organs. ${ }^{1-4}$ Usually considered under the overarching term "heterotaxy", ${ }^{2-7}$ two specific subsets exist within the overall group. ${ }^{2-7}$ The existence of an isomeric arrangement of the lungs and bronchial tree was long since established as a discriminating feature, but arguments have raged as to whether isomerism might exist within the heart. ${ }^{5-15}$ It has now been shown that, when assessed on the basis of the extent of the pectinate muscles relative within the atrial appendages relative to the atrial vestibules, cardiac isomerism is a real entity. ${ }^{13}$ The two subsets thus identified encompass a wide range of anatomical variants, characterized by complex systemic and pulmonary venous connections, and complicated intracardiac anatomy. The strategies for treating these patients remain equally complicated. To date, most publications assessing the significance of the isomeric arrangements have been based on necropsy studies, case reports, or small case series. ${ }^{8-13}$ Only limited large scale clinical studies have emphasized the potential significance of the isomeric features. ${ }^{14-22}$ With all of this in mind, we have assessed the published clinical and necropsy data to determine the influences of right as opposed left isomerism on the surgical outcomes, including re-interventions.

\section{Methods}

We identified publications than might relate to the presence of isomerism in the setting of so-called "visceral heterotaxy". From these publications, we collated and analyzed the anatomical descriptions of the systemic and pulmonary venous connections, and the presence of associated cardiac and non-cardiac anomalies, paying special attention to surgical and non-surgical treatments used and their outcomes. The search engines employed were PubMed, Google Scholar, Cochrane Database for Systematic Reviews, Cochrane Central Register of Controlled Trials, Ovid Medline, ACP Journal Club, Ovid EMBASE, and Database of Abstracts of Review of Effectiveness in all languages. We made an individualized review of 62 investigations, ${ }^{1-23,26-64}$ incorporating these findings with the results of US Scientific Registry of Transplant Recipients Data, along with results emanating from Loma Linda University. ${ }^{24,25}$ Due to limited sample sizes, the heterogeneity of clinical state at the time of surgical intervention, inclusion of necropsy data, and the difficulties in selection of appropriate cardiac quantifiable end points, it did not prove possible to perform a meta-analysis.

\section{Incidence}

On the basis of the New England Regional Infant Cardiac Program, those with isomeric atrial appendages can be inferred to account for just under one-twentieth of all infants with congenital cardiac malformations. ${ }^{26}$ The reported incidence in necropsy studies is around 3\%, but no more than $1.5 \%$ in echocardiographic investigations. ${ }^{7,9-13,27}$ Isomerism is said to occur in approximately one out of every 5000-7000 live births with patients of Asian descent. ${ }^{9-13,27}$ Right isomerism is more frequently reported in necropsy studies compared to surgical series, reflecting the complexity of the cardiac anomalies, poor natural outcome, inoperability, and increased risk of sepsis. ${ }^{7,9-13,27}$

\section{Results}

\section{Demographics}

The age of patients with right isomerism at initial diagnosis, as assessed from the literature, ranges from birth to 22.3 years, with a median of 7.7 months. Among survivors, approximately nine-tenths presented in the neonatal period, having been recognized at birth in almost two-thirds. Half of these patients required prostaglandin infusion at presentation to maintain oxygen saturation. ${ }^{14-19,22}$ For those with left isomerism, age at initial diagnosis ranged from birth to 35 years, with a median of 2 days. Of these two-thirds were females, whereas only half of those with right isomerism were female. Up to one-sixth of reported patients with left isomerism have extracardiac lesions but normal hearts. We have excluded these individuals from 
further study. It remains the case, nonetheless, that approximately one-fifth of reported patients with left isomerism died shortly after birth, with about half not having surgery and dying during infancy. ${ }^{16,17,20}$

\section{Diagnosis}

Even now, it remains difficult to distinguish between the subsets on the basis of clinical identification of the atrial appendages. ${ }^{27-32}$ Almost all children with right isomerism are in sinus rhythm. Abnormal p wave morphology and slow atrial rhythm are associated with left isomerism, with complete heart block occurring in about $10 \% .{ }^{30}$ Howell-Jolly bodies, a prominent feature in right isomerism, are found on peripheral blood smears. ${ }^{29,30}$ The status of spleen can be confirmed by abdominal ultrasound or a radionuclide spleen scan. $^{2,3,6-13,15}$ Since intestinal malrotation is a frequently associated lesion, a barium study is frequently advocated, especially for those with right isomerism. ${ }^{16,30}$ Tracheobronchial anatomy, best revealed using a high voltage aortopulmonary view. ${ }^{6,11,12,30}$ can be used to distinguish right versus left isomerism. ${ }^{12,23,31} \cdot{ }^{30-32}$ It is bronchial arrangement that correlates best with the arrangement of the atrial appendages. ${ }^{31-33}$ This is significant, since it still remains a problem specifically to diagnose specifically the features of the atrial appendages. ${ }^{4,31}$ When seeking to make the diagnosis by inference, echocardiography assessment of the abdominal great vessels and hepatic venous drainage is more accurate than assessment of the abdominal organs. ${ }^{27,29}$ Although prenatal diagnosis can be made by echocardiography, this had no impact on survival. ${ }^{32}$ Transesophageal echocardiography is becoming helpful in confirming the diagnosis (Figure 1). It is computed tomography, and/or three-dimensional cardiac magnetic resonance, nonetheless, that now provides the best comprehensive assessment. ${ }^{34,35}$

\section{Surgical Anatomy}

\section{The intracardiac anatomy of right isomerism}

Both atrial appendages have similar external and internal configurations. ${ }^{2,3,7,12,13,30}$ They have a broad junction, separated by an extensive terminal groove, with the venoatrial components. Presence of pectinate muscles extending to the crux of the heart on both sides is the essential diagnostic feature. Because of the presence of bilateral morphologically right appendages, the pulmonary venous connections will always be anatomically anomalous, even when the veins connect to one or other of the atrial chambers (Figure 2). The connection is usually through a midline confluence that connects to the atrial roof (Figures 3 and 4 ). The channel often becomes stenotic. The superior caval veins, frequently bilateral, connect directly with the atrial roofs. The coronary sinus is universally absent. Hence, the coronary veins drain directly into the atrial cavities, usually at the level of the vestibules, but on occasion at a distance from the atrioventricular junction. ${ }^{36}$ It is most unusual to find interruption of the inferior caval vein when there is right isomerism. In some instances, all of the pulmonary veins can drain to either the right-sided or the left-sided atrial chamber, while all the systemic veins connect to the other atrial chamber. Such quasi-usual or quasi-mirror-imaged venous drainages do not detract from the fact that the atrial arrangement remains that of right isomerism.

The atrial chambers typically connect to the ventricles through a common atrioventricular junction, and often the atrial septum is no more than a myocardial strand. Although found most frequently with double inlet right ventricle, each of the atrial chambers can be connected to its own ventricles across the common junction. Half of the heart will then be concordantly connected, while the other half will be discordantly connected. The biventricular atrioventricular connection, therefore, is mixed. It is frequent in this setting to have duplicated atrioventricular nodes, producing the so-called Monckeberg sling. ${ }^{37}$ It is very unusual to find concordant ventriculo-arterial connections. Most usually the connections are double outlet right ventricle or transposition. Obstruction or atresia of the outflow tract of the morphologically right ventricle is expected. It is very rare to find a common arterial trunk, or tetralogy of Fallot. When pulmonary atresia is present, then the pulmonary arteries are usually fed through an arterial duct, which can be right or left-sided (Figure 5). The aortic arch, along with the cardiac apex, can be right-sided or left-sided.

\section{The Intracardiac Anatomy of Left Isomerism}

It is again the extent of the pectinate muscles relative to the atrioventricular junctions that serves as the 
distinguishing feature of the morphologically left appendage. In left isomerism, there is always a smooth vestibule between the margin of the appendage and the cardiac crux. Since both atriums will have a morphologically left appendage, the pulmonary venous connections are morphologically normal, albeit that symmetrical drainage, with two pulmonary veins connecting to an atrium on each side, is frequent. When all the pulmonary veins are connected to one of other of the atrial cavities, it is frequent to find quasi-usual or quasi-mirror-imaged venous drainage. It is the rule to find anomalies in the systemic venoatrial connections, most usually interruption of the inferior caval vein, with continuation through the azygos venous system (Figures 6 and 7). The connection can then be to either a right-sided or a left-sided superior caval vein. Such interruption can also be found with usual atrial arrangement, even when there are multiple spleens and left bronchial isomerism. ${ }^{16}$ The intracardiac anatomy is then usually normal.

Bilateral superior caval veins are frequent, but in the form of a coronary sinus, usually with one or other draining through a coronary sinus. When there is a coronary sinus, it receives the coronary venous drainage. When the coronary sinus is absent, the coronary veins connect directly to the atrial chambers.

The atrial septum is much better formed in left as opposed to right isomerism. Biventricular and mixed atrioventricular connections are also more frequent than in right isomerism, usually with a common atrioventricular junction, as are concordant ventriculo-arterial connections. It is much more frequent with left isomerism, therefore, to find patterns producing relatively normal circulations. If obstruction is found within the ventricular outflow tracts, it is usually the left ventricle that is involved. Because of the isomeric left atrial appendages, the sinus node is always abnormal, typically being hypoplastic and displaced towards the atrioventricular junctions. ${ }^{37}$

\section{Surgical Management}

Optimal management of the two sub-sets remains nebulous. ${ }^{14-25,38}$ The subsets, nonetheless, are best segregated on the basis of right versus left isomerism. The markedly different features will post different surgical challenges. Overall surgical management has evolved with time. Moderately hypothermic cardiopulmonary bypass at $32^{\circ} \mathrm{C}$, using cold blood cardioplegia, is now the most popular technique, replacing continuous cardiopulmonary bypass with low-flow perfusion, brief periods of deep hypothermic circulatory arrest, and deep hypothermic circulatory arrest with selective cerebral perfusion. ${ }^{14-25,38}$ Venous cannulation can be problematic in both subsets because of the systemic venous anomalies. Direct cannulation is preferred because of the likely complexity of any intraatrial repair. The intracardiac anomalies are more likely to be amenable to complete repair in those with left isomerism, with biventricular repairs reported in one-third to one-half of patients. ${ }^{14-25,38}$ Such repairs, nonetheless, often require complex atrial and ventricular baffle procedures. ${ }^{14-25,38}$ The complex malformations associated with right isomerism, in contrast, usually preclude biventricular repair.

\section{Pulmonary arterial banding}

Pulmonary artery banding, using conventional and absorbable bands, has been performed as initial palliation in premature infants with low body weight and/or severe associated non-cardiac congenital anomalies. The lesions requiring such treatment include unbalanced complete atrioventricular septal defects, multiple muscular septal defects, and those with common atriums. ${ }^{14-25,38}$ These are found in either sub-set.

\section{Systemic-to-pulmonary arterial shunts}

These procedures are required most frequently in those with right isomerism. Over time, descriptions have been provided of the use of the modified Blalock-Taussig shunt, the Waterston-Cooley shunt, and the UKC shunt. ${ }^{14-25,39,40}$ Construction of such shunts is usually followed by repair of totally anomalous pulmonary venous connection, with a superior cavopulmonary connection added for those requiring emergency intervention in the setting of a functionally univentricular heart. ${ }^{14-25,39-41}$ Alternatively, the shunt can be performed concomitantly with rechanneling of the totally anomalous pulmonary venous return. ${ }^{15,18,41}$ Others have delayed the repair of obstructed totally anomalous pulmonary venous connection by inserting a hybrid stent. ${ }^{22}$

\section{Atrial septation}


Several techniques have been described for construction of interatrial baffles. When the left superior caval vein is unroofed, septation has been achieved using an obliquely positioned patch. In association with anomalous pulmonary venous return, some have used one patch for direction of the pulmonary veins to the systemic ventricle, and a second patch to complete atrial septation. When the orifice of the left superior caval vein is further from the midline, the coronary sinus has been reconstructed using a xenopericardial patch, again with a separate patch used to complete atrial septation. ${ }^{14-25}$

\section{Superior cavopulmonary connection}

This procedure has been undertaken as a prelude to creation of the Fontan circulation in both subsets. Because of the presence of bilateral sinus nodes in right isomerism, and the unusual location of sinus node in left isomerism, the superior caval vein should be transected at the level of the right pulmonary artery, retaining a small length of superior caval wall. Dissection along the atrial roof should be undertaken with great care to avoid potential injury to the sinus nodal artery. ${ }^{37,41}$

Systemic-to-pulmonary artery shunt or superior cavopulmonary connection or Norwood's procedure with concomitant pulmonary artery augmentation

Restoration of an unrestricted pulmonary arterial pathway is essential when repairing compromised pulmonary arteries. These operations have been described on an individualized basis. ${ }^{14,15,41}$

\section{Superior cavopulmonary connection with concomitant rechanneling of totally anomalous pul- monary venous connection}

This combination, required in the setting of right isomerism, has again been described on an individualized basis. ${ }^{15,18,38}$

\section{The Kawashima procedure}

This technique was designed for those with left isomerism and azygos continuation of an interrupted inferior caval vein. The hepatocardiac venous and coronary sinus blood is redirected into the left-sided atrial chamber (Figures $6 \mathrm{C}$ and $6 \mathrm{D}){ }^{43}$

\section{Extracardiac and intracardiac conduits}

Subsequent to the development of the extracardiac Fontan circulation, this operation was employed in the setting of isomerism with systemic venous anomalies. It was extended into its fourth generation by using a fenestrated partly intracardiac conduit. ${ }^{44}$

\section{Completion of the Fontan circulation}

In those deteriorating after a previous Glenn procedure as part of staged palliation, or after the Kawashima repair with development of pulmonary arteriovenous malformations, the hepatic venous return has been redirected using either an extracardiac polytetrafluoroethylene conduit, or a partly intracardiac fenestrated conduit (Figures 8 and 9). ${ }^{43-47,64}$ Other investigators have created brachial arteriovenous fistulas for treatment of the pulmonary arteriovenous malformations. ${ }^{8,9,43-47}$

\section{Rechanneling of totally anomalous pulmonary venous connection}

These procedures are required in all of those with right isomerism, even if the pulmonary veins connect to the heart. Several guidelines have emerged. Minimal manipulation of the pulmonary veins is advised during dissection of the pulmonary venous confluence. So as to minimize the thickness of the anastomosis, small endocardial-to-endocardial bites are optimal. The extracardiac confluence can usually be explored by lifting the cardiac apex, dislocating it into the right thoracic cavity. A large unrestrictive anastomosis can then be made by using a posterior approach. When the connection is obstructed, routine left atrial augmentation is usually required. This can be achieved using a fenestrated Dacron patch. Should the obstructive connection have resulted in suprasystemic pulmonary arterial pressures, then we prefer adjustable ligation of the vertical vein. ${ }^{48,49}$ Circulatory arrest has often been required in neonates to optimize visualization. The pectinated 
atrial wall is an additional complicating factor when seeking to create an unobstructed communication with the pulmonary venous confluence. ${ }^{48,49}$

Total cavopulmonary connection with concomitant rechanneling of totally anomalous pulmonary venous connection

This procedure has been recommended in those with right isomerism when the totally venous connection is unobstructed. ${ }^{15,38}$

\section{Rechanneling of the persistent left superior caval vein}

Techniques described include simple ligation, division and reimplantation to the right-sided atrium, construction of an intra-atrial, placement of an interposition graft to the to right-sided atrium, and anastomosis of the vein to the left pulmonary artery. ${ }^{19,50}$

\section{Transcatheter approaches, or surgical ligation of major aortopulmonary collateral arteries}

Collateral channels have been managed either by embolization or by surgical ligation. Transcatheter angioplasty and insertion of expandable stents have been employed for enlargement of stenotic anomalous pulmonary veins, pulmonary arterial stenosis, and stenosed venous circuits following cardiac transplantation. ${ }^{15-18,20,22,25}$

\section{Cardiac transplantation}

Using appropriate reconstructive techniques, orthotopic cardiac transplantation has been performed in selected individuals with right isomerism, a functionally single ventricle, and totally anomalous pulmonary venous connection. The techniques include interposed spiral saphenous vein grafts, superior and inferior intraatrial baffles, a composite cavopericardial graft to the right brachiocephalic vein, a diaphragmatic pericardial tunnel, and separate right and left pulmonary venous cuffs. Dacron conduits placed between the right-sided atrium and the left superior caval vein, along with counter-clockwise rotation of an anastomosis to the left sided inferior caval vein, have permitted restoration of continuity of the systemic venous return. ${ }^{24,25,51-53}$

\section{Correction of associated cardiac anomalies}

Additional associated congenital cardiac anomalies are all been treated on their own merits. ${ }^{14-22}$

\section{Outcomes in the short and long term}

Despite the advances made in diagnosis and surgical treatment, the overall prognosis remains less than satisfactory in either the long or the short term. ${ }^{14-22}$ To an extent, this is hardly surprising, since right isomerism has long been recognized as one of the worst forms of congenital heart disease. The malformations in right isomerism, for the most part, preclude biventricular repair. ${ }^{15,18,19,21-23,41,43-47}$ Reported mortalities range between one-third and one-half for construction of a systemic-to-pulmonary arterial shunt and repair of totally anomalous pulmonary venous connection repair, while comparable mortalities have ranged between one-third and three-quarters for functionally univentricular repair. ${ }^{15-23,46}$ Of those in whom a superior cavopulmonary connection had been constructed, up to one-quarter proceeded to completion of the Fontan circulation, but even in this group there was reported mortality of one-fifth. ${ }^{15-23,42}$ Totally anomalous pulmonary venous connection was identified as a poor prognostic indicator, associated with a median age at death of of 3 months, with the addition of pulmonary atresia resulting in a median age at death of 1 month. ${ }^{9}$ But, since totally anomalous pulmonary venous connection is universally present in those with right isomerism, it is likely the combination with pulmonary atresia that is the straw that breaks the back of the camel.

Reported mortalities for those with left isomerism and functionally univentricular repair range between onefifth and one-third, but for those suitable for biventricular repair, mortality has been reported between zero and one-quarter. ${ }^{16,17}$ Of those undergoing univentricular palliation, however, only seven-tenths are in NYHA class I, as opposed to almost all of those suitable for biventricular repair. ${ }^{15-23,55}$ Longer term prognosis at present is equally depressing. At one year, $85 \%$ of those with right isomerism are dead, along with more than half of those with left isomerism. ${ }^{15-23,55}$ The situation, of course, is further tilted against those with right 
isomerism, since in absence of the spleen they have an increased risk of sepsis. ${ }^{15-23,55-57}$ In most reported series, unsurprisingly, survival is better when the lesions permit biventricular repair. ${ }^{14-23,55-58}$ Such biventricular repair has been reported in a small proportion of patients with right isomerism. ${ }^{15,18,19,21-23,41,43,47-49}$ And for those not receiving surgical intervention, death is inevitable. ${ }^{28}$ Incremental risk factors for death have been identified as obstructed totally anomalous pulmonary venous connection, restenosis of pulmonary veins, and pulmonary atresia.

\section{Discussion}

The evidence is now strongly in favour of discriminating between the recognized sub-sets of so-called "visceral heterotaxy" on the basis of isomerism of the atrial appendages. ${ }^{4-13}$ With the advances now made possible through the increased resolution of multi-detector computed tomography, and the ability to reconstruct the three-dimensional datasets, it is possible not only to recognize the features of the atrial appendages, but also to correlate the cardiac findings with the arrangements of thoracic and abdominal organs. The clinical findings endorse the conclusions long since made based on autopsy studies. Thus, right isomerism is usually, but not universally, accompanied by absence of the spleen. It is this feature that is believed to render such individuals susceptible to infection. The isomeric right appendages are the harbingers of the most severe cardiac and complex congenital malformations. ${ }^{2-13}$ Left isomerism is typically associated with polysplenia, but even the presence of multiple spleens does not protect against splenic incompetence. ${ }^{15-23,54}$

The markedly different features of right as opposed to left isomerism obviously pose different surgical challenges. Detailed knowledge of the likely co-existing cardiac anomalies, therefore, is advantageous prior to surgical intervention. Recognition of the presence of bilateral morphologically right atrial appendages, for example, enables the surgeon to anticipate the presence of bilateral sinus nodes. Recognition of isomeric left appendages, in contrast, alerts to an abnormal location of the atrial pacemaker. ${ }^{37,60}$ Appropriate precautions, therefore, should be taken to avoid injury not only to the sinus node, or nodes, but also their arteries. ${ }^{42}$

In those with left isomerism, the surgeon should anticipate interruption of the inferior caval vein. If performing a superior cavopulmonary connection, and prior to ligating the azygos venous channel, an enlarged azygos vein associated with an intact inferior caval vein should always be differentiated from azygos continuation of an interrupted vein. When the inferior caval vein connects directly to the atrial chambers, it may connect to either the left or right-sided atrium. In left isomerism, this should be distinguished from bilateral connection of hepatic veins. In those with right isomerism, in contrast, a hepatic vein often co-exists with an inferior caval vein (Figures 8 and 9 ). ${ }^{2-5,9-11}$

Although the arrangement of the inferior caval vein tends to distinguish those with left from right isomerism, this is not the case for the superior caval vein. At least half of patients with right isomerism, and up to twothirds of those with left isomerism, have bilateral superior caval veins. ${ }^{2-13,15,19}$ When bilateral superior caval veins are present with right isomerism, each connects to the top corner of its atrium. This can make it difficult to divert the vein to the right-sided atrium, should this be required, or because of its short length even to the right superior caval vein. ${ }^{50}$ In left isomerism, in contrast, both superior caval veins are connected to atrial chambers in the fashion of drainage through a coronary sinus, although often unroofed. ${ }^{2,7,10,11}$ The hepatic venous connections are of particular concern in this setting. The veins usually connect to one atrium, but sometimes to both atriums, or to both sides of a common atrium (Figures 7 and 8). ${ }^{5,7,9-13}$ Such direct hepatic venous connections are not only found when the inferior caval vein is interrupted, but also when it connects directly to one or other atrial chamber. When performing the Kawashima procedure, search should be made for any interconnections between the inferior caval vein and the hepatic veins below their entry to the heart. ${ }^{5,7,9-13,43-47}$ Preoperative demonstration of such venous arrangements can facilitate construction of fenestrated Fontan pathways (Figure 9). ${ }^{44-46}$

Although not always recognised, totally anomalous pulmonary venous connection is universal in the setting of right isomerism, since both atrial appendages are morphologically right. Even should all pulmonary veins connect directly to one of the atrial chambers, such connections will be anatomically anomalous. ${ }^{2,3}$ The cardiac venous return is often obstructed. ${ }^{2-5,14-22}$ The presence of pectinate muscles all around the 
muscular atrioventricular vestibules creates additional problems in producing an unobstructed pulmonary venous pathway. ${ }^{2-15,19-22}$ Pulmonary venous obstruction is the more frequent when the pulmonary arteries are hypoplastic, atretic, or discontinuous. ${ }^{2-15,19-22}$ Severe obstruction to pulmonary venous flow may mask the clinical importance of the pulmonary venous anomaly. ${ }^{2-22}$ On our institute, we continue to perform adjustable ligation of the vertical vein, routine left atrial augmentation, and interatrial septal fenestration when we recognise obstructive totally anomalous pulmonary venous connection, or when we encounter suprasystemic pulmonary arterial hypertension subsequent to weaning from bypass. ${ }^{48,49}$ It is almost certainly the intrinsic anatomic and histopathologic differences in the pulmonary veins of individuals with right isomerism that accounts for the higher incidence of reoperation when compared to individuals with lateralized atrial appendages. ${ }^{14,15,20,21,48,49,61-63}$

The pulmonary venous connections will always be anatomically normal when there is left isomerism, but such normally connected veins can be bilaterally symmetrically, with two connecting to each atrium with a morphologically left appendage. ${ }^{2-5,11}$ This produces a significant distance between the right and leftsided pulmonary veins, ${ }^{5,9-13}$ making for elongated and complex suture lines for any potential intraatrial baffle. ${ }^{14-22}$ The complexity of the required baffles can explain in part the reported incidence of postoperative arrhythmias, which has ranged between less than one-tenth to one-half. Also contributing to these problems are the absence, hypoplasia, or abnormal location of sinus node, along with abnormalities in the pathways for atrioventricular conduction. ${ }^{14-21,59,60}$

Another well recognized problem in the setting of left isomerism is the development of pulmonary arteriovenous malformations following the Kawashima operation, seen in up to three-fifths of cases (Figure 10). ${ }^{45,46,64}$ This is attributed to isolation of the lungs from exposure to hypothetical hepatic factors. Redirection of the hepatic venous return to the systemic venous circuit during completion of the Fontan circulation has been shown to result in subsequent resolution. ${ }^{45,46,64}$

Within the overall group, regurgitation of the common atrioventricular valve is a known risk factor for postoperative mortality, particularly after functionally univentricular repair. A systemic-to-pulmonary arterial shunt is known to cause volume overload, aggravating the regurgitation, and increasing mortality following completion of the Fontan circulation. ${ }^{15,21,43-47}$ This has led to suggestions that the common valve be repaired or replaced before completion of the operations. ${ }^{41,45-47}$ Cardiac transplantation also represents a significant technical challenge. This may reflect previous palliative procedures, but is further exacerbated by the complex systemic and pulmonary venous anomalies. ${ }^{24,25}$ Even though the technical issues have largely been resolved, transplantation in the setting of isomerism remains associated with increased postoperative complications. Early and late survival is poor compared to other forms of congenital cardiac diseases. ${ }^{24,25,51-53}$

\section{Conclusions}

Based on the information available to us from the literature, and including our own experience, we are convinced that multimodality imaging is now capable of characterizing and delineating the precise anatomical details of the two sub-sets of individuals born with isomeric atrial appendages. These investigations should now permit the mandatory assessment of the pulmonary venous return required in the setting of right isomerism to unmask concealed pulmonary venous obstruction. In those with left isomerism, such investigations should now delineate the patterns of drainage of the inferior caval and hepatic venous systems. Given the ongoing high mortalities of those requiring a combination of shunting procedures, or functionally univentricular repair, it seems prudent to reassess the conventional strategies for management. In particular, the option of cardiac transplantation should now be systematically evaluated as an alternative pathway of management for those deemed to be at high risk.

\section{Author's contribution}

\begin{tabular}{lllll}
\hline Author's name & Concept/ design & Data analysis / interpretation & Drafting article & Critical revis \\
\hline Ujjwal Kumar Chowdhury & $?$ & $?$ & $?$ & $?$ \\
Robert H. Anderson & $?$ & $?$ & $?$
\end{tabular}




\begin{tabular}{lllll}
\hline Author's name & Concept/ design & Data analysis/ interpretation & Drafting article & Critical revis \\
\hline Diane E. Spicer & $?$ & $?$ & $?$ & $?$ \\
Lakshmi Kumari Sankhyan & $?$ & $?$ & $?$ & $?$ \\
Niraj Nirmal Pandey & $?$ & $?$ & $?$ & $?$ \\
Shikha Goja & $?$ & $?$ & $?$ & $?$ \\
Palleti Rajasekar & - & $?$ & $?$ & $?$ \\
Balaji Arvind & - & $?$ & $?$ & $?$ \\
Doniparthi Pradeep & - & $?$ & $?$ & $?$ \\
\hline
\end{tabular}

\section{References}

1. Ivemark BI. Implications of agenesis of the spleen on the pathogenesis of cono-truncus anomalies in childhood: an analysis of the heart malformations in the splenic agenesis syndrome, with fourteen new cases. Acta Paediatr Scand 1958; 44: 9-100.

2. Anderson RH, Spicer DE, Loomba R. Is an Appreciation of Isomerism the Key to Unlocking the Mysteries of the Cardiac Findings in Heterotaxy? J Cardiovasc Dev Dis. 2018; 5:11.

3. Anderson RH. Atrial structure in the presence of visceral heterotaxy. Cardiol Young. 2000; 10: 299302.

4. Jacobs JP, Anderson RH, Weinberg PM, et al. The nomenclature, definition and classification of cardiac structures in the setting of heterotaxy. Cardiol Young 2007; 17: 1-28

5. Van Praagh R, Van Praagh S. Atrial isomerism in the heterotaxy syndromes with asplenia, or polysplenia, or normally formed spleen: an erroneous concept. Am J Cardiol 1990; 66: 1504-1506.

6. Van Mierop LHS, Gessner H, Schiebler GL. Asplenia and polysplenia syndromes. In: Bergsma, ed. Birth defects, original articles series, 8. Baltimore: Williams and Wilkins, 1972: 74-82.

7. Uemura H, Ho SY, Devine WA, Anderson RH. Analysis of visceral heterotaxy according to splenic status, appendage morphology, or both. Am J Cardiol 1995; 76: 846-849.

8. Min JY, Kim CY, Oh MH, et al. Arrangement of the systemic and pulmonary venous components of the atrial chambers in hearts with isomeric atrial appendages. Cardiol Young 2000; 10(4): 396-404.

9. Phoon CK, Neill CA. Asplenia syndrome: insight into embryology through an analysis of cardiac and extracardiac anomalies. Am J Cardiol 1994; 73: 581-7.

10. Sharma S, Devine W, Anderson RH, Zuberbuhler JR. The determination of atrial arrangement by examination of appendage morphology in 1842 heart specimens. Br Heart J 1988; 60: 227-231.

11. Rubino M, Van Praagh S, Kadoba K, et al. Systemic and pulmonary venous connections in visceral heterotaxy with asplenia. Diagnostic and surgical considerations based on seventy-two autopsied cases. J Thorac Cardiovasc Surg 1995; 110: 641-650.

12. Macartney FJ, Partridge JB, Shinebourne EA, et al. Identification of atrial situs. In: Anderson RH, Shinebourne EA, eds. Paediatric cardiology 1977. Edinburgh \& London: Churchill Livingstone, 1978: 16-26.

13. Uemura H, Anderson RH, Yagihara T. Surgical implications in hearts with isomeric atrial appendages. In: Karp RB, editor. Advances in cardiac surgery, vol. 7. St Louis: Mosby; 1996. p. 101-36.

14. Mahnke CB, Sandor GG, Boyle GJ, Webber SA. "Masked" pulmonary venous obstruction in patients with isomerism of the right atrial appendages: an overstated association. Cardiol Young 2002; 12: $113-118$.

15. Hashmi A, Abu-Sulaiman R, McCrindle BW, et al. Management and outcomes of right atrial isomerism: a 26-year experience. J Am Coll Cardiol 1998; 31: 1120-1126.

16. Gilljam T, McCrindle BW, Smallhorn JF, et al. Outcomes of left atrial isomerism over a 28-year period at single institution. J Am Coll Cadiol 2000; 36: 908-916.

17. Vodiskar J, Clur SA, Hruda J, et al. Left atrial isomerism: biventricular repair. European Journal of Cardio-thoracic Surgery 37 (2010) 1259-1263.

18. Heinemann MK, Hanley FL, Van Praagh S, et al. Total anomalous pulmonary venous drainage in newborns with visceral heterotaxy. Ann Thorac Surg 1994; 57: 88-91. 
19. Yun TJ, Al-Radi OO, Adatia I, et al. Contemporary management of right atrial isomerism: effect of evolving therapeutic strategies. J Thorac Cardiovasc Surg. 2006; 131: 1108-1113.

20. Morales DL, Braud BE, Booth JH, et al. Heterotaxy patients with total anomalous pulmonary venous return: improving surgical results. Ann Thorac Surg. 2006; 82: 1621-1627.

21. Hancock Friesen CL, Zurakowski D, Thiagarajan RR, et al. Total anomalous pulmonary venous connection: an analysis of current management strategies in a single institution. Ann Thorac Surg 2005; 79: 596-606.

22. Chaturvedi RR, Van Arsdell GS, Jacques F, Lee KJ. Delayed repair of right atrial isomerism with obstructed total anomalous pulmonary venous drainage by hybrid stent insertion between the leftsided atrium and pulmonary venous confluence. J Thorac Cardiovasc Surg. 2012; 144: 271-273.

23. Partridge J. The radiological evaluation of atrial situs. Clin Radiol 1979; 30: 95-103.

24. Duong SQ, Godown J, Soslow JH, et al. Heart transplantation in heterotaxy syndrome is associated with reduced survival and increased cost of care.Thorac Cardiovasc Surg. 2019; 157(2): 730-740.

25. Larsen R, Eguchi J, VenderDussen L, et al. Heart transplantation: children with visceral heterotaxy and complex congenital heart disease. J Am Coll Cardiol 1997; 29: Suppl A: 105.

26. Fyler DC. Report of the New England Regional Infant Cardiac Program. Pediatrics 1980; 65 (Suppl): 376-461.

27. Stumper OFW, Sreeram N, Elzenga NJ, Sutherland GR. Diagnosis of atrial situs by transesophageal echocardiography. Am JH Cardiol 1990, 16, 442-446.

28. Pennekamp P, Menchen T, Dworniczak B, Hamada H. Situs inversus and ciliary abnormalities: 20 years later, what is the connection? Cilia. 2015 Jan 14; 4(1): 1.

29. Sapire DW, Ho SY, Anderson RH, Rigby ML. Diagnosis and significance of atrial isomerism. Am J Cardiol 1986; 58: 342-346.

30. Cohen MS, Anderson RH, Cohen MI, et al. Controversies, genetics, diagnostic assessment, and outcomes relating to the heterotaxy syndrome. Cardiol Young. 2007; 17 (suppl 2): 29-43.

31. Loomba RS, Pelech AN, Shah PH, Anderson RH. Determining bronchial morphology for the purposes of segregating so-called heterotaxy. Cardiol Young. 2016; 26: 725-737.

32. Yim D, et al., Disharmonious Patterns of Heterotaxy and Isomerism: How Often Are the Classic Patterns Breached? Circ Cardiovasc Imaging, 2018 11(2): p. e006917.

33. Tremblay C, Loomba RS, Frommelt PC, et al. Segregating bodily isomerism or heterotaxy: potential echocardiographic correlations of morphological findings. Cardiol Young. 2017: 27: 1470-1480.

34. Wang JK, Li YW, Chiu IS, et al. Usefulness of magnetic resonance imaging in the assessment of venoatrial connections, atrial morphology, bronchial situs, and other anomalies in right atrial isomerism. Am J Cardiol. 1994; 74: 701-704.

35. Kersting-Sommerhoff BA, Diethelm L, Stanger P, et al. Evaluation of complex congenital ventricular anomalies with magnetic resonance imaging. Am Heart J 1990,120: 133-142.

36. Uemura H, Ho SY, Anderson RH, Devine WA, et al. The surgical anatomy of coronary venous return in hearts with isomeric atrial appendages. J Thorac Cardiovasc Surg 1995; 110: 436-444.

37. Smith A, Ho SY, Anderson RH, Connell MG, et al. The diverse cardiac morphology seen in hearts with isomerism of the atrial appendages with reference to the disposition of the specialized conduction system. Cardiol Young 2006; 16: 437-454.

38. Chowdhury UK, Airan B, Kothari SS, et al. Univentricular heart with total anomalous pulmonary venous connection. Indian Heart Journal 1999; 51: 630.

39. Chowdhury UK, Venogopal P, Kothari SS, et al. Criterions for selection of patients for, and results of a new technique for construction of the modified Blalock-Taussig shunt.Cardiol Young 2006; 16: 463-473.

40. Watterson KG, Wilkinson JL, Karl TR, Mee RBB. Very small pulmonary arteries: central end-to-side shunt.Ann Thorac Surg 1991; 52: 1132-1137.

41. Alsoufi B, McCracken C, Schlosser B, et al. Outcome of multistage palliation of infants with functional single ventricle and heterotaxy syndrome. J Thorac Cardiovasc Surg 2016; 151: 1369-1377.

42. Chowdhury UK, Airan B, Subramaniam G, et al. Specific issues after extracardiac Fontan operation 
at mid-term follow up. Systemic ventricular function, growth potential, arrhythmia and thromboembolism. Ann Thorac Surg 2005; 80: 665-72

43. Setyapranata S, Brizard CP, Konstantinov IE, et al. Should we always plan a Fontan completion after a Kawashima procedure?European Journal of Cardio-thoracic Surgery 2011; 40: 1011-1015.

44. Vargas FJ, Mayer JE Jr, Jonas RA, et al. Anomalous systemic and pulmonary venous connections in conjunction with atriopulmonary anastomosis (Fontan-Kreutzer). Technical considerations. J Thorac Cardiovasc Surg 1987; 93: 523-532.

45. Bartz PJ, Driscoll DJ, Dearani JA, et al. Early and late results of the modified Fontan operation for heterotaxy syndrome: 30 years of experience in 142 patients. J Am Coll Cardiol 2006; 48: 2301-2305.

46. Jonas RA. Surgical management of the neonate with heterotaxy and long-term outcomes of heterotaxy. World J Pediatr Congenit Heart Surg. 2011;2:264-274.

47. Marathe SP, Zannino D, Cao JY, et al. Heterotaxy is not a risk factor for adverse long-term outcomes after Fontan completion. Ann Thorac Surg. 2020;110:646-653.

48. Chowdhury UK, Subramaniam G, Joshi K, et al. Rechanneling of totally anomalous pulmonary venous connection with or without vertical vein ligation: Results and guidelines for candidate selection. J Thorac Cardiovasc Surg, 2007; 133: 286-294.

49. Chowdhury UK, Singh S, George N, et al. Adjustable vertical vein ligation in supracardiac totally anomalous pulmonary venous connection: A clinical report of 99 patients. Journal of Clinical Cardiology and Cardiovascular Interventions, 2020; 3(7); Doi:10.31579/2641-0419/075.

50. Takach TJ, Cortelli M, Lonquist JL, Cooley DA. Correction of anomalous systemic venous drainage: transposition of left SVC to left PA. Ann Thorac Surg. 1997; 63(1): 228-230.

51. Chartrand C. Pediatric cardiac transplantation despite atrial and venous return anomalies. Ann Thorac Surg 1991; 52: 716-721.

52. Vouhe' PR, Tamisier D, Le Bidois JL, et al. Pediatric cardiac transplantation for congenital heart defects: surgical considerations and results. Ann Thorac Surg 1993; 56: 1239-1247.

53. Razzouk AJ, Gundry SR, Chinnock RE, et al. Orthotopic transplantation for total anomalous pulmonary venous connection associated with complex congenital heart disease. J Heart Lung Transplant 1995; 14: 713-717.

54. Vazquez J, Lopez Gutierrez JC, Garnez M, et al. Biliary atresia and the polysplenia syndrome: Its impact on final outcome. J Pediatr Surg 1995; 30: 485-487.

55. Ichikawa H, Sawa Y, Fukushima N, et al. Late assessment after biventricular repair for isomerism heart. Ann Thorac Surg 2005; 80: 50-55.

56. Anagnostopoulos PV, Pearl JM, Octave C, et al. Improved current era outcomes in patients with heterotaxy syndromes. Eur J Cardiothorac Surg 2009; 35: 871-877.

57. Takabayashi S, Shimpo H. Surgical repair of coronary sinus orifice atresia with persistent left superior vena cava in heterotaxia. Gen Thorac Cardiovasc Surg. 2007; 55(5): 197-199.

58. Serraf A, Bensari N, Houyel L, et al. Surgical management of congenital heart defects associated with heterotaxy syndrome. Eur J Cardiothorac Surg 2010; 38: 721-727.

59. Ozawa Y, Asakai H, Shiraga K, et al. Cardiac rhythm disturbances in heterotaxy syndrome. Pediatr Cardiol. 2019;40:909-913.

60. Ho SY, Fagg N, Anderson RH, et al. Disposition of the atrioventricular conduction tissues in the heart with isomerism of the atrial appendages: its relation to congenital complete heart block. J Am Coil Cardiol 1992; 20: 904-910.

61. Yamaki S, Tsunemoto M, Shimada M. Quantitative analysis of pulmonary vascular disease in total anomalous pulmonary venous connection in sixty infants. J Thorac Cardiovasc Surg 1992; 104: 728-735.

62. Jenkins KJ, Sanders SP, Orav EJ, et al. Individual pulmonary vein size and survival in infants with totally anomalous pulmonary venous connection. J Am Coll Cardiol 1993; 22: 201-206.

63. Gaynor JW, Collins MH, Rychik J, et al. Long-tern outcome of infants with single ventricle and total anomalous pulmonary venous connection. J Thorac Cardiovasc Surg 1999; 117: 506-514.

64. Kim SJ, Bae EJ, Lee JY, et al. Inclusion of hepatic venous drainage in patients with pulmonary arterio-venous fistulas. Ann Thorac Surg 2009; 87: 548-553. 


\section{Figure Legends}

Figure 1. The echocardiographic image in the apical 4 chamber view shows both atrial appendages to be morphological left (red asterisks). Note the dilated coronary sinus (CS). The inset shows the subcostal axial view, revealing a venous channel (yellow asterisk) coursing posterior to the descending thoracic aorta (red asterisk). This is the interrupted inferior caval vein. The atrioventricular connections are mixed with right-handed ventricular topology (RV and LV). The modified high parasternal view in panel B shows the continuation of the inferior caval vein through the azygos vein to the left superior caval vein. Abbreviations : LA, left atrium; LSCV, left superior caval vein; LV, left ventricle; RA, right atrium; RV, right ventricle]

Figure 2: Volume rendered images (A, anterior view, and B, left anterior oblique view) in a patient with right isomerism showing both appendages to be morphologically right (*right sided morphologically right appendage, ${ }^{* *}$ left sided morphologically right appendage). Panel C, showing a posterior view, and panel D, a right lateral view, show the all four pulmonary veins draining at the junction of superior caval vein (SCV) with right atrium (RA) (black arrow in D).]

Figure 3: Axial computed tomographic images in a patient with right isomerism show, in panel A, a transverse midline liver. Panel B shows bilateral right bronchial morphology. The coronal image in panel $\mathrm{C}$ shows bilateral superior caval veins, each draining to its own atrium (R: right-sided morphologically right atrium; L: left-sided morphologically left atrium). The volume rendered images in panels D and E show the rightsided $(*)$ and left-sided appendages $(* *)$, both morphologically right. As seen in panel $\mathrm{F}$, all pulmonary veins (arrowheads) drain to the right-sided atrium

Figure 4: The volume rendered images, shown in panel A in right anterior oblique view, in panel B in left anterior oblique view, and in panel $\mathrm{C}$ in posterior view, show bilateral appendages of right morphology, with all pulmonary veins joining the right-sided atrium. Abbreviations: RA: right-sided atrium; LA: leftsided atrium; RV: right ventricle; LV: left ventricle; RSPV: right superior pulmonary vein; RIPV: right inferior pulmonary vein; LSPV: left superior pulmonary vein; LIPV: left inferior pulmonary vein, *right sided morphologically right atrial appendage, ${ }^{* *}$ left sided morphologically right atrial appendage]

Figure 5: Panels A and B show axial images, and Panels $\mathrm{C}$ and $\mathrm{D}$ show volume rendered images from a patient with right isomerism and pulmonary atresia. All the pulmonary veins (indicated by arrowheads) are connected to the right-sided atrium with a morphologically right appendage (RA). Note the co-existing defect in the oval fossa (white asterisk in B) and the perimembranous ventricular septal defect (black asterisk in B and C). Oblique axial image, as seen in panel E, shows pulmonary atresia (black arrow) with good-sized confluent pulmonary arteries. Oblique coronal image, seen in panel F, shows a patent arterial duct (indicated by star) feeding the pulmonary arteries. Abbreviations : RAA: right atrial appendage; LA: left-sided atrium; RV: right ventricle; LV: left ventricle; LPA: left pulmonary artery; RPA: right pulmonary artery.]

Figure 6: Panel A shows a coronal image, and panel B a volume rendered image, from a patient with left isomerism. There is azygos continuation of the inferior caval vein, with the azygous vein $(*)$ draining into the superior caval vein (SCV). Panels $\mathrm{C}$ through $\mathrm{E}$ show volume-rendered images subsequent to repair using the Kawashima procedure, with the superior caval vein connected to the pulmonary arteries. Abbreviations : RPA: right pulmonary artery; LPA: left pulmonary artery.

Figure 7: Panel A is an axial image from a patient with left isomerism, showing multipler spleens (yellow circle). The coronal minimal intensity projection image in panel B shows left bronchial isomerism. The volume rendered images seen in panel $\mathrm{C}$, an anterior view, shows the hepatic veins (arrowed) draining into the right-sided atrium, which has a morphologically left appendage. Panel D, a sagittal image, demonstrates azygos $(*)$ continuation of the inferior caval vein into the superior caval vein (SCV).

Figure 8: The volume rendered image (Panel A) from a patient with left isomerism shows hemiazygos (black arrows) continuation of the inferior caval vein into the left-sided superior caval vein (LSCV), which has been anastomosed to the pulmonary artery. Panel B shows separate hepatic veins (arrowheads) rerouted to the right pulmonary artery $(\mathrm{RPA})$ via a graft $(*)$. The maximum intensity projection image in panel $\mathrm{C}$ shows a 
pulmonary arteriovenous malformation (thick white arrow) in the left lower lobe.

Figure 9: The volume rendered image (Panel A) and the oblique coronal images (Panels B and C) are from a patient with left isomerism in whom the left-sided superior caval vein (LSCV) has been anastomosed to the left pulmonary artery (RPA). The hepatic veins (arrowheads) and the inferior caval vein have been connected to the right pulmonary artery (RPA) via a conduit whiuch is partly extracardiac and partly interatrial.

Figure 10: The volume rendered images, shown in a posterior view (panel A), a left anterior oblique view (panel B), and an anterior view (panel C), are from a postoperative patients with left isomerism who developed pulmonary arteriovenous malformations. There is hemizaygos $(*)$ continuation of the inferior vena cava into the superior caval vein (SCV), which in turn has been anastomosed to the pulmonary arteries. The maximum intensity projection image in panel D shows a pulmonary arteriovenous malformation (yellow arrow) in the left lower lobe. Abbreviations : RPA: right pulmonary artery; LPA: left pulmonary artery.

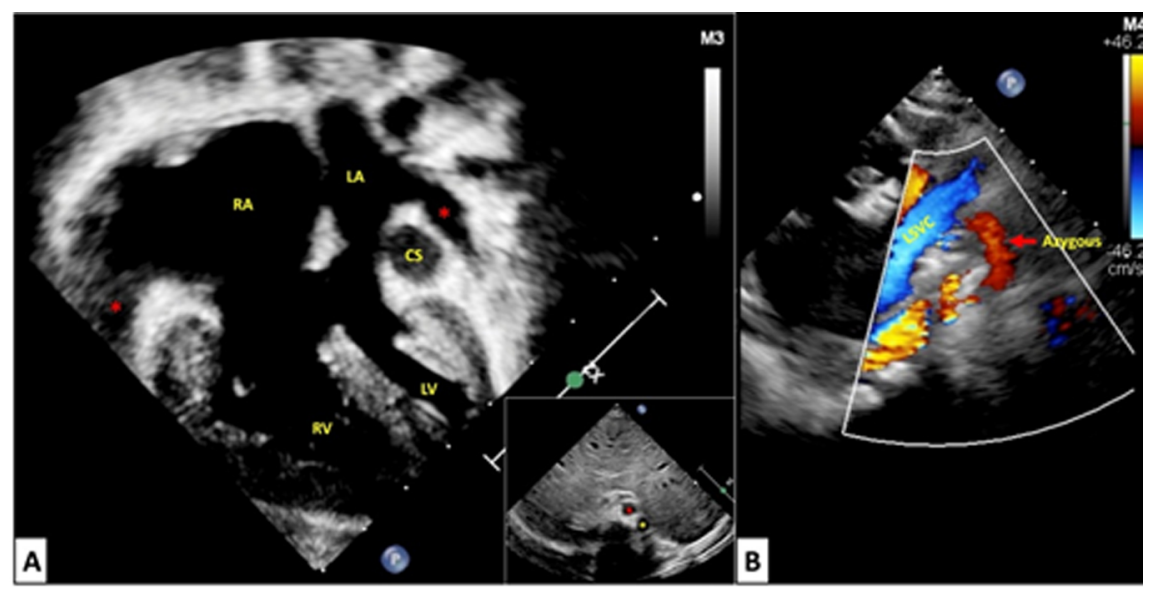



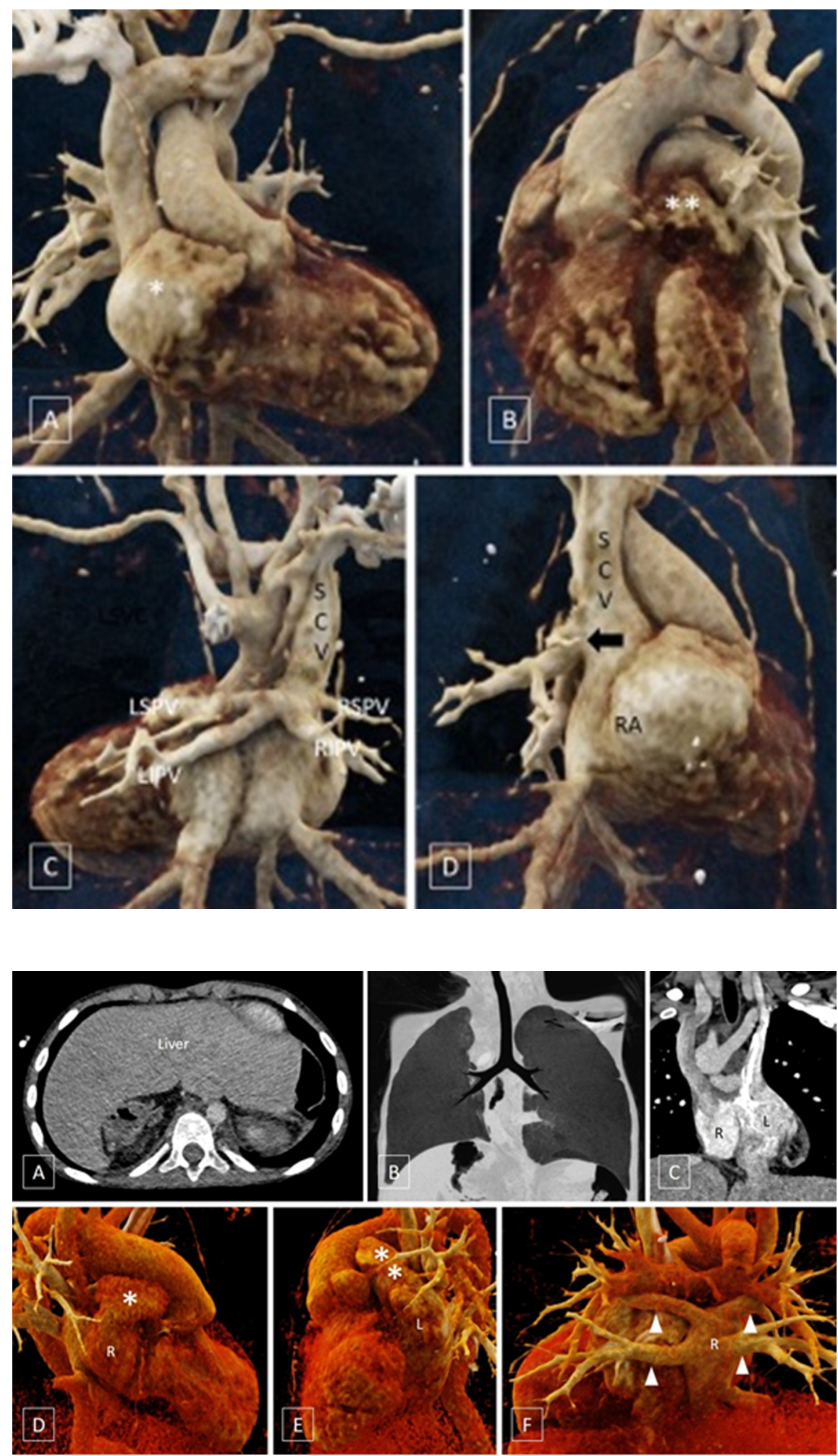

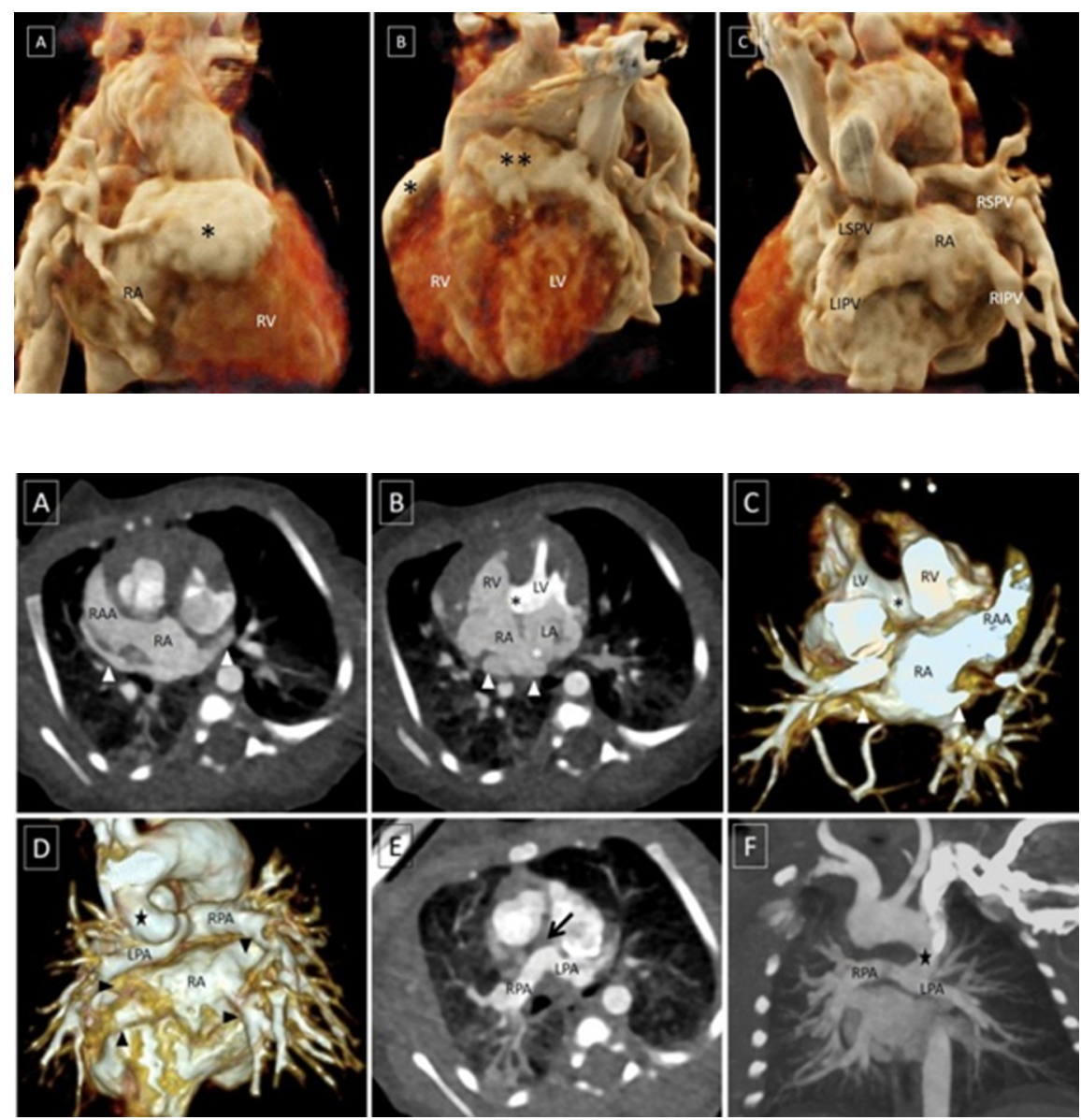


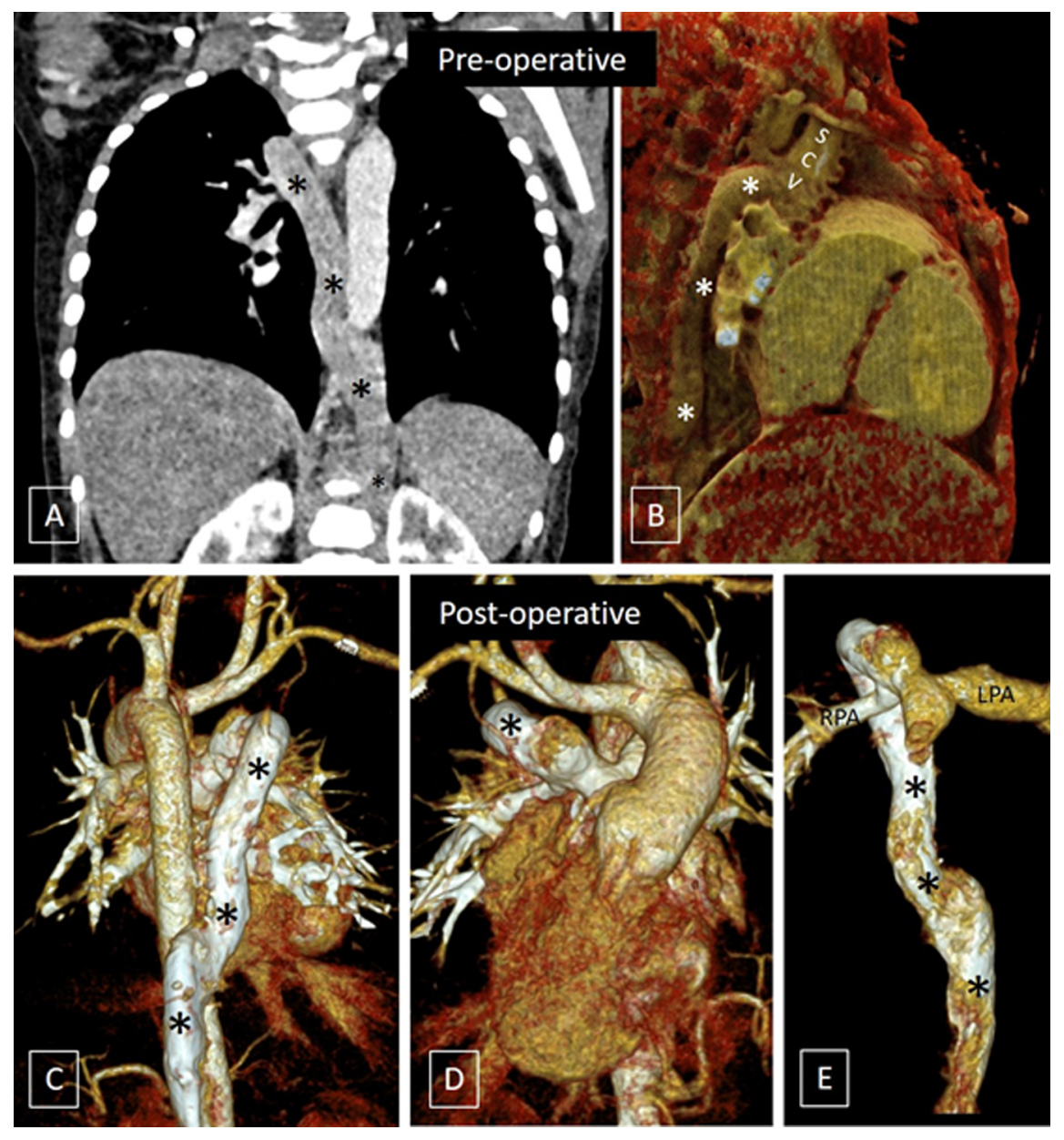



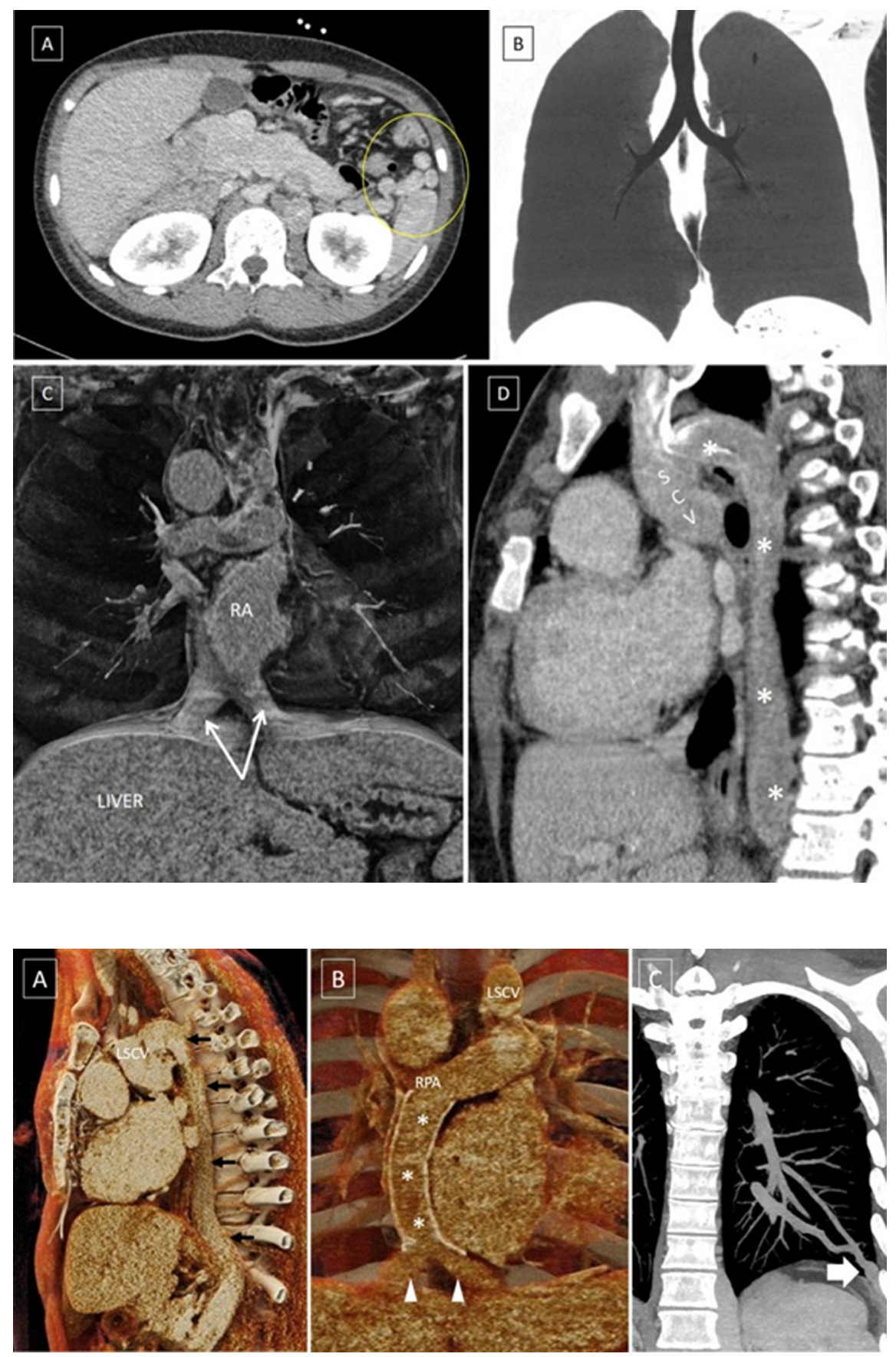

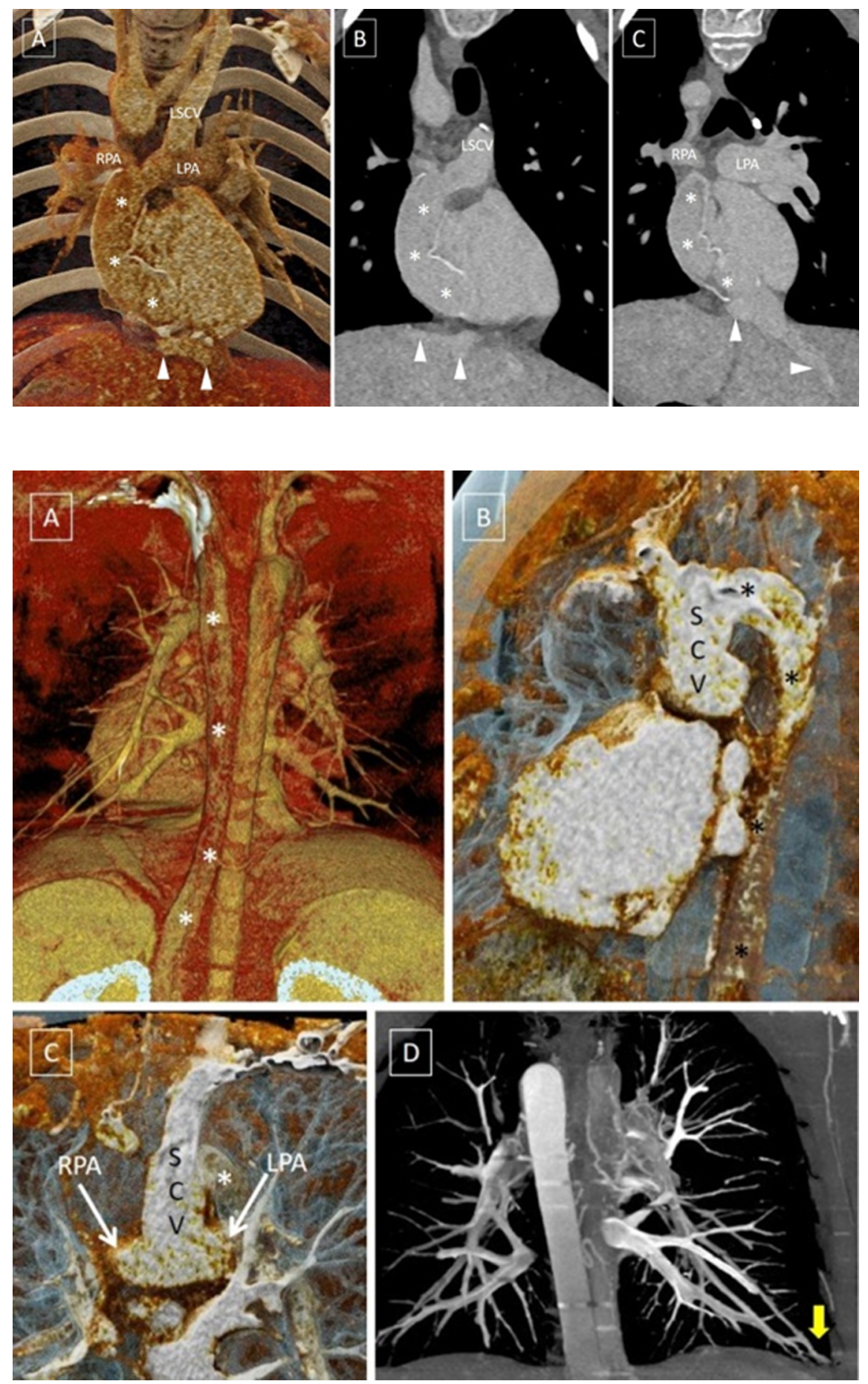